\title{
Laser-testurizazio prozesurako eredu matematikoa
}

\section{(A mathematical model for the laser texturing process)}

\author{
Oihane Murua*, Jon Iñaki Arrizubieta, Marta Ostolaza, Aitzol Lamikiz, Eneko Ukar \\ Mekanika Saila, Bilboko Ingeniaritza Eskola (UPV/EHU)
}

\begin{abstract}
LABURPENA: Proiektu honetan laser-testurizazio prozesuaren zenbakizko eredua garatu da. Horretarako, lehendabizi laser-testurizazio prozesuaren informazioa bildu da, ondorengo programazioan errealitatearen hurbilpen egokia simulatu ahal izateko. Aurrez aipatutako fabrikazio-prozesu honen jakintza eskuratu ostean, ekintza berbera irudikatzen duen eredu matematikoa sortzeko beharrizana ikusi da. Horrela, lanaren metodologia hiru pausotan antolatu da: lehenik, laser-testurizazio prozesu baten eredu hurbildu bat sortu da; ondoren, prozesu errealaren saiakuntza esperimentalak egin dira; eta azkenik, lortutako emaitzen arteko alderaketaren bitartez eredua balioztatu da. Ereduaren garapena Matlab-eko PDE moduluaz baliatuz egin da eta pieza bateko gainazaleko puntu zehatzen lurruntzea simulatzeko gaitasuna dauka. Simulatutako ereduan sortzen diren kraterrak, nanosegundoko pultsuak igortzen dituen laser baten bitartez erreproduzitzeko saiakuntzak egiten dira. Laser-testurizazioa simulatzen duen eredua egiaztatu ahal izateko, simulazioetatik lortutako emaitzak saiakuntza esperimentaletan lortutakoekin alderatu dira eta emaitzen artean korrelazio oso ona lortu da: kraterren diametroan eta sakoneran 5 eta 0,5 mikretako erroreak lortuz, hurrenez hurren. Horrela, garatu den eredu matematikoa eta jarraitutako prozedura balioztatuta gelditu dira.
\end{abstract}

HITZ GAKOAK: laser-testurizazioa, eredu matematikoa, Matlab, Stellite 6, kraterra.

ABSTRACT: The aim of this project is the development of a mathematical model, which represents the laser texturing process. To that end, firstly, information on the fundamentals of the laser texturing process is gathered. After the analysis of the state-of-the-art of laser texturing processes, the development of a mathematical model representing the phenomena that takes place in the laser texturing process is carried out. Therefore, the methodology followed for such task consists on 3 steps: creating an approximate model, performing experimental testing of the process, and conducting the validation of the model based on the experimental results obtained. The development of the model is based on the PDE module of Matlab and aims to simulate the vaporization phenomenon in localized areas of the surface. The craters created by the model are later reproduced in experimental tests, by employing a laser, which emits nanosecond pulses. For the purpose of validating the laser texturing model, the results obtained in the simulations and the experimental data are compared and a good correlation is obtained: errors below 5 and 0.5 microns regarding the diameter and the depth of the crater, respectively. Consequently, the mathematical model and the followed procedure are validated.

KEYWORDS: laser texturing, mathematical model, Matlab, Stellite 6, crater.

* Harremanetan jartzeko / Corresponding author: Oihane Murua. Ingeniaritza Mekanikoko Saila, Plaza Torres Quevedo, 1 (48013 Bilbao. Bizkaia, Euskal Herria). - omurua005@ikasle.ehu.eus - https://orcid.org/0000-0002-2058-3042

Nola aipatu / How to cite: Murua, Oihane; Arrizubieta, Jon Iñaki; Ostolaza, Marta; Lamikiz, Aitzol; Ukar, Eneko (2022). «Lasertesturizazio prozesurako eredu matematikoan. Ekaia, 42, 2022, 301-316. (https://doi.org/10.1387/ekaia.22926).

Jasotze-data: 2021, ekainak 21; Onartze-data: 2021, urriak 21.

ISSN 0214-9001 - elSSN 2444-3255 / (c) 2022 UPV/EHU

(c) (i) $\odot$ Lan hau Creative Commons Aitortu-EzKomertziala-LanEratorririkGabe 4.0 Nazioartekoa

(c) ${ }_{\text {BY }}$ NC No lizentzia baten mende dago 
Oihane Murua, Jon Iñaki Arrizubieta, Marta Ostolaza, Aitzol Lamikiz, Eneko Ukar

\section{SARRERA}

Laser bidezko testurizazio-prozesua, ingelesetik datorren Laser Surface Texturing (LST), patroi zehatz bat sortzeko asmoz gainazaleko materiala egituratzean oinarritzen da. Fabrikazio-prozesu honen eginkizuna aurpegi baten testura edo gainazal-egituraketa zehatza lortzea da, oro har, pultsukako laser batez baliatuz. Laser-testurizazio prozesurako eredu matematikoa Matlab software komertziala erabiliz garatu, eta jarraian, eredu hori esperimentalki balioztatu da.

Industria mailan laser-testurizazioaren lehen pausoak 90eko hamarkadaren erditik aurrera agertu ziren. Eta orduz geroztik, Israelgo Technion Institutu Teknologikoaren [1] aitzindaritzapean etengabeko garapenean dagoen fabrikazio-prozesua da. Gaur egun arte egindako ikerketen artean, laser mota desberdinekin egindako testurak aztertzea, testurizazio-prozesu esperimentalaren azterketa, egituratutako gainazalen portaera modelizatzea eta laser-testurizazio prozesua bera modelizatzea aurkitzen dira [2]. Alabaina, laser-testurizazioaren teknologiak oraindik ez du lortu heldutasun nahikoa eta bere erabilera oraindik ez dago oso zabaldua industria mailako zenbait sektoretan dituen kostu altu eta produktibitate baxuarengatik.

Orokorrean, LST prozesuaren ereduaren diseinu optimoa sortzeak ebaluazio-denbora eta konputazio-kostu altua daukate [3]. Bestalde, ereduen garapenerako kostu altuak inbertsio bat dira, eta edozein proba esperimentalen aurretiko pauso garrantzitsuenetako bat bihurtu dira.

Fabrikazio-prozesuen modelizazioak dakartzan onurei dagokienez, prozesuko parametro egokiak lortzeko historikoki jarraitzen den proba-hutsegite metodoaren iterazio kopurua arintzea nabarmentzen da. Laser-testurizazio prozesuaren modelizazioaren inguruko ikerkuntzen harira, bi ikerlerro nagusi bereiz daitezke: alde batetik, testura jakin baten portaeraren azterketa helburu dutenak; eta bestetik, laser-egituraketa prozesua bera simulatzen dutenak.

Kasu honetan laser-testurizazio prozesua modelizatu denez, jarraian azaldutako ikerketak dira aurrekari garrantzitsuenak. Hasteko, laser-egituraketa prozesuaren lehen simulazio-ikerketa 2008an argitaratu zen Numerical Simulation of Laser Surface Micro-Texturing izenpean [4]. Ikerketa horren garapenean, ANSYS softwarea erabili zen eta elementu finituen (FEM) bidez Newton-Rapson metodoa aplikatu zuten testuraren krater eta tenperatura eremuaren analisia egiteko. Urteak aurrera joan ahala, gero eta argiago ikusten da ikerketa horri egin dakizkioken hobekuntzak. Esaterako, laserraren pultsuak gainazalean indar bat izango balira bezala sartzen zituzten, eta hortaz, ezin daiteke aurreikusi laser baten pultsuek gainazalean sartzen duten beroa, eta indarrek gainazalean sortzen duten eragina besterik ezin da aztertu. Gainera, plasmagatiko zuzenketa erabiltzen zuten kraterra- 
ren sakonera lortzeko, hots, tenperatura batetik aurrera laserraren eragina nulutzat hartzen zuten. Beste alde batetik, laserraren intentsitate eta pultsu kopuru desberdinentzat simulazio anitz egin zituzten (1. irudia). Hala ere, lortzen zituzten krater sakonerak ez ziren esperimentalki konprobatu, beraz, ez dago jakiterik simulazioetan erabilitako hurbilpenak egokiak ziren.

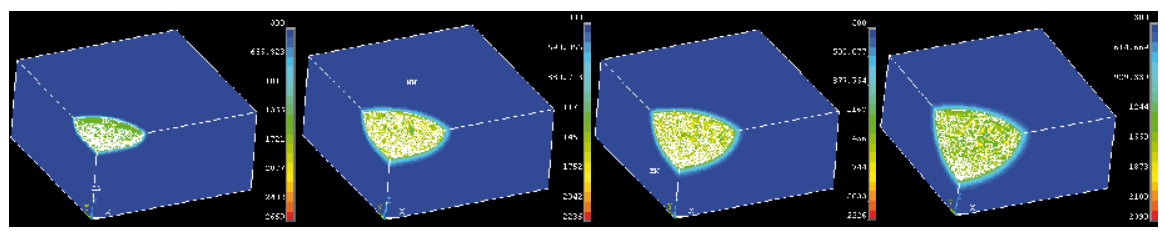

(a)

(b)

(c)

(d)

1. irudia. Numerical Simulation of Laser Surface Micro-Texturing ikerketako emaitzak, lortutako kraterra pultsu kantitate desberdinekin [4, 3]: (a) pultsu bat; (b) 3 pultsu; (c) 5 pultsu; (d) 20 pultsu.

2018an Jieyu Xian ikertzaileak eta bere taldeak laser-testurizazio prozesuan bertan lortzen diren emaitzen hurbilpenak egiteko eredua garatu zuten [5]. Ikerkuntza horretan egituraketa-prozesuan deuseztatuko den materialaren sakonera eta azalera iragartzeko eredua sortu zuten. Orokorrean, lan horren bitartez, geruza anitzeko neurona-sare bat entrenatu eta iragarpen algoritmo bat sortu zuten. Aipagarria da lortutako emaitza simulatuak eta esperimentalak nahiko onak zirela, baina eredu horren izaera guztiz bestelakoa da. Izan ere, azken finean neurona-sarea entrenatzeko prozesua oso luzea izaten da, saiakuntza esperimental askorekin, eta hau eragozpena da azkartasuna bilatzen denean.

Azken urteetan laser-egituraketa prozesuaren zenbait eredu garatu dira, eta horietatik jarraian azalduko diren biak COMSOL Multiphysics software komertzialaz baliatuz egin dira. Ikerketa hauetako lehenengoan [6], testuraren sorrera simulatzen da, baina aurkezturiko lanak hainbat gabezia erakusten ditu. Adibidez, ikerketa horretan eredua balioztatzeko laserraren parametro jakin batzuk erabiltzen dira bakarrik. Gainera, hasierako gainazalaren ezaugarriei ez zaie garrantzirik ematen, eta horrek zerikusia dauka mikrometro eskalan lan egiten denean. Horrez gain, ondorioetan aipatzen da ablazio-eredua bera bakarrik ez zela gai kraterraren itxura hurbildua lortzeko (2. irudia). Hori dela eta, material itsatsiaren portaera egoki hurbiltzeko jariakin eredu bat gehitu behar zela ondorioztatu zuten. COMSOL Multiphysics softwarerekin garatutako bigarren ikerketan, femtosegundo mailako pultsu bidezko laser-testurizazio eredua garatzen da [7]. Aurreko artikuluaren software bera erabili arren, kasu horretan pultsu ultramotzeko laser baten egituraketa-prozesuko fenomeno fisikoen eredua lortzea zen helburu. Horretarako, bi tenperaturako eredua sortu zuten, hots, femtosegundotako pultsuek modeloa ez desegonkortzeko laserraren beroa bi eta- 
Oihane Murua, Jon Iñaki Arrizubieta, Marta Ostolaza, Aitzol Lamikiz, Eneko Ukar

patan sartzen zuten. Tenperatura bi etapatan banatzea ideia ona izan daitekeen arren, honen egiaztatze esperimentalik ez dagoenez, ezin daiteke esan lortutako simulazioen emaitzak zentzuzkoak direla.

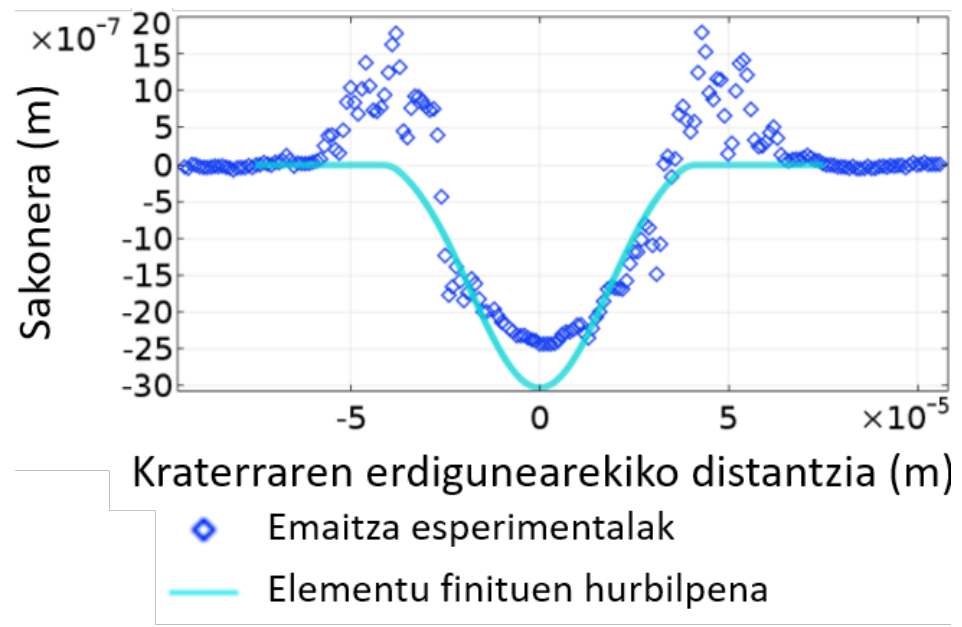

2. irudia. Ablazio-ereduaren eta emaitza esperimentalen konparaketa [6].

Proiektu honen helburua lengoaia matematikoko Matlab softwarearen bitartez laser-testurizazio prozesua simulatzen duen zenbakizko eredua garatzea da, betiere dagokion egiaztatze esperimentala duelarik. Ereduan, laserra bero-iturri baten moduan simulatzen da eta plasma zuzenketarik ez da aplikatzen. Gainera, laserrak berak beroa transmititzen duen fenomenoa ahalik eta errealen irudikatzeko, testurizazioan erabiltzen diren pultsu labur bezala sartzen da bero-iturria egituratu nahi den gainazalean. Horretaz gain, modelizazioan funtsezkoa den balidazio esperimentala aurrera eraman da.

\section{METODOLOGIA}

Proiektu honetan jarraitutako metodologiaren harira, modelizazioa eta saiakuntza esperimentalak oinarrizko atalak dira. Bi atal hauetatik, lehenengo eredua garatzen da, eta ondoren, saiakuntzak egiten dira. Horrela, saiakuntzen emaitzez baliatuz zenbakizko eredua egiaztatzen da.

Laser-testurizazio prozesuaren ereduak jarraitzen duen eskema segidan erakusten den 3. irudian adierazten da. Bertan, argi ikusten da alde batetik sarrerako parametroak zehaztu behar direla, eta hauek abiapuntu izanik eredu termikoa lanean jartzen da. Eredu termikoan, elementu finituen problema ebazteko sarea zehazten da. Sarearekin eta sarrerako parametroekin 
batera programa nagusia exekutatzen da, hots, eremu termiko eta kalkulu geometrikoen ebazpena egin den programaren zatia.

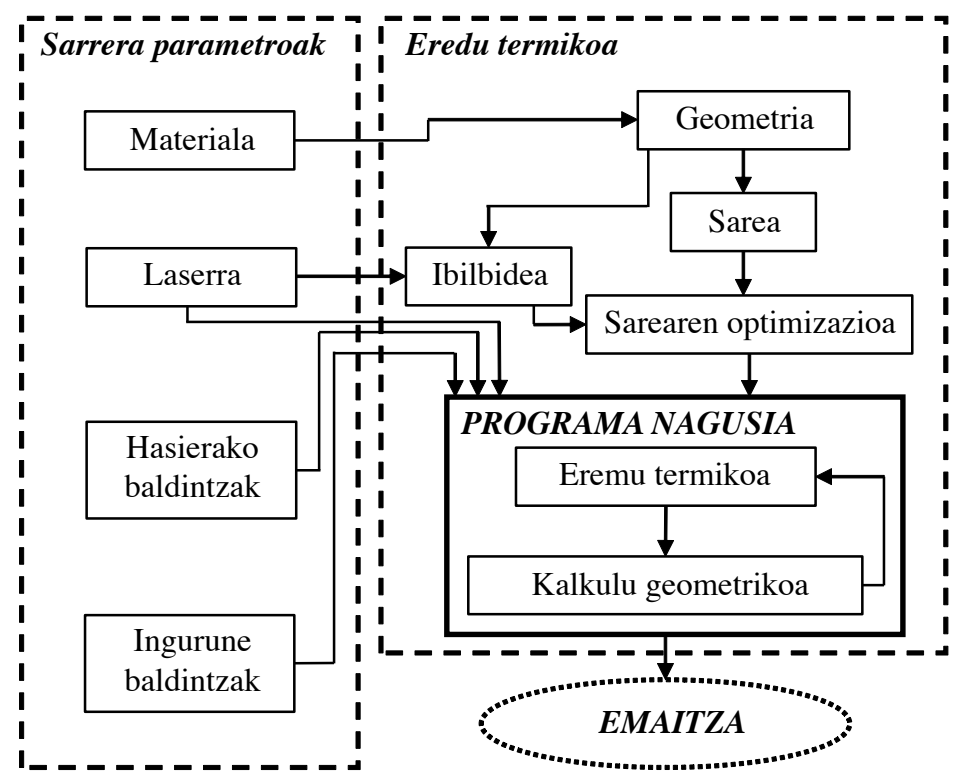

3. irudia. Ereduaren garapenaren eskema.

Ereduarekin hasi aurretik beharrezko parametroak zehaztu behar dira: materialaren datuak eta makinaren parametroak, eta beren balioak saiakuntza esperimentaletan erabili diren berdinak zehazten dira. Proiektu honetan erabili den materiala kobalto (Co) oinarria duen Stellite 6a da, zehazki 1. taulako konposizioa duena. Material ezaguna eta industriako zenbait sektoretan (petrolio eta gasa, automozioa, aeronautika eta biomedikoa) erabilia da dituen higadurarekiko, tenperatura altuekiko eta korrosioarekiko erresistentzia altuarengatik.

1. taula. Stellite 6aren konposizio kimikoa (\%).

\begin{tabular}{ccccccccccc}
\hline $\mathrm{Co}$ & $\mathrm{Cr}$ & $\mathrm{W}$ & $\mathrm{Ni}$ & $\mathrm{Fe}$ & $\mathrm{Mn}$ & $\mathrm{C}$ & $\mathrm{Mo}$ & $\mathrm{Si}$ & $\mathrm{P}$ & $\mathrm{S}$ \\
\hline 58,00 & 29,99 & 3,99 & 2,47 & 1,56 & 1,47 & 1,07 & 0,94 & 0,68 & 0,006 & $<0,002$ \\
\hline
\end{tabular}

Stellite 6aren egituraketa egiteko TRUMPF fabrikatzaileen TruMark Station 5000 makina erabili da, egoera solidoko zuntz motako laserra duena. Prozesuko parametroen kontrolerako, laserrak TruTops Mark softwarea barneratuta dauka, non sortu nahi den testuraren ibilbidea bertan zehaztu daitekeen. 
Oihane Murua, Jon Iñaki Arrizubieta, Marta Ostolaza, Aitzol Lamikiz, Eneko Ukar

\section{EREDUAREN OINARRIAK}

Ereduaren oinarri teorikoa, eremu termikoari dagokion eroapen iragankorreko bero-transferentziaren problema ebazteko jarraian adierazten den ekuazio diferentzialak ezartzen du.

$$
\rho \cdot C_{p} \cdot \frac{\partial u}{\partial t}-\nabla(k \cdot \nabla u)=f \quad \text { non } \quad \begin{aligned}
& u: \\
& \rho: \text { Tenperatura } \\
& C_{P}: \text { Bentsitatea } \\
& f: \text { Bero-iturria } \\
& k: \text { Eroankortasun termikoa }
\end{aligned}
$$

2. taula. Stellite 6aren tenperaturaren menpeko propietateak.

\begin{tabular}{cccc}
\hline $\begin{array}{c}\text { Tenperatura } \\
(\mathrm{K})\end{array}$ & $\begin{array}{c}\text { Dentsitatea } \\
\left(\mathrm{kg} \cdot \mathrm{m}^{-3}\right)\end{array}$ & $\begin{array}{c}\text { Bero espezifikoa } \\
\left(\mathrm{J} \cdot \mathrm{kg}^{-1} \cdot \mathrm{K}^{-1}\right)\end{array}$ & $\begin{array}{c}\text { Eroankortasun } \\
\text { termikoa } \\
\left(\mathrm{W} \cdot \mathrm{m}^{-1} \cdot \mathrm{K}^{-1}\right)\end{array}$ \\
\hline 293 & 8.400 & 425 & 13,00 \\
393 & 8.360 & 475 & 14,50 \\
470 & 8.330 & 500 & 16,00 \\
530 & 8.300 & 525 & 16,64 \\
620 & 8.275 & 550 & 18,00 \\
700 & 8.240 & 575 & 18,48 \\
730 & 8.228 & 600 & 19,50 \\
775 & 8.210 & 625 & 20,01 \\
860 & 8.180 & 650 & 21,10 \\
910 & 8.152 & 675 & 21,77 \\
950 & 8.130 & 725 & 22,50 \\
1.020 & 8.100 & 750 & 22,50 \\
1.100 & 8.060 & 1.150 & 22,50 \\
1.193 & 8.020 & 1.400 & 22,50 \\
1.270 & 7.980 & 1.680 & 22,50 \\
1.293 & 7.970 & 1.920 & 22,52 \\
1.393 & 7.970 & 2.150 & 22,60 \\
1.493 & 7.970 & 2.320 & 22,68 \\
1.593 & 7.970 & 2.415 & 22,75 \\
1.693 & 7.968 & 2.450 & 22,82 \\
1.793 & 7.967 & 700 & 22,88 \\
1.893 & 7.966 & 700 & 22,94 \\
2.000 & 7.965 & 700 & 23,00 \\
\hline & & & \\
\hline & & & \\
\hline
\end{tabular}

Bero-transferentzia problema hau Matlab-eko PDE (Partial Differential Equation) moduluaren bitartez ebatzi da. Beraz, problema termikoa kalku- 
latzeko, PDE moduluak beharrezkoak dituen aldagai guztiak definitu behar dira. Hori dela eta, materialaren datuak tenperaturaren menpe taularatu dira 2016an Wei Ya eta bere ikertzaile taldeak argitaratutako artikulutik eskuratutako balioekin (2. taula) [8]. Stellite 6aren ablazioa modelizatzeko bere lurruntze-tenperatura $\left(T_{v}\right)$ zehaztea garrantzitsua da, baina balio zehatza ez da aurkitu bibliografian. Hori dela eta, materialaren aleazio nagusien (Co-Cr) lurruntze-tenperaturak alderatuz, ereduan $T_{v}=2.671{ }^{\circ} \mathrm{C}$ zehaztu da Stellite 6aren lurruntze-tenperatura gisa. Bestalde, laser prozesuetan materialaren absortibitatearen balioa $(\alpha)$ zehaztu beharreko propietatea da, eta kasu honetan $\alpha=0,5$ eko balio konstantea finkatu da.

Materialaren datuak zehaztu ostean laserraren espezifikazio guztiak finkatu behar dira. Lehenik eta behin, Trumark Station 5000aren laser-izpiak $45 \mu \mathrm{m}$-ko erradioa eta $10^{\circ}$-ko dibergentzia angelua ditu. Bestalde, argi izan behar da, laser-testurizazioa ahalik eta garbiena eta azkarrena izan behar dela, urtutako material itsatsia ez delako simulatuko. Horrela, egituraketa azkarra egitearen bitartez urtutako material kantitatea txikiagoa eta egindako hurbilpena hobea izango dira. Horregatik, laserraren potentzia maximoan lan egitea erabaki da, hots, $50 \mathrm{~W}$-ko potentzia nominalarekin. Pultsuko potentziaren balio maximoa lortzeko, laserrari ezarritako maiztasuna $f=50 \mathrm{kHz}-\mathrm{koa}$ eta pultsuen iraupena $t=250 \mathrm{~ns}$-koa dira. Laserrak piezan eragiten duen beroiturria, piezaren absortibitatearen, laserraren beraren potentziaren eta erasoko dion azaleraren menpekoa da, jarraian erakusten den adierazpenarekin lortzen dena. Erabiliko den adierazpen hau laserraren pultsuen iraupenaren menpe dagoenez, denbora-tartearen arabera balio bat edo beste izango du bero-iturriak.

$$
\begin{array}{llll}
f=\alpha \cdot \frac{P}{A} \quad t \in[(n-1) \cdot T, d t+(n-1) \cdot T] & & \alpha: & \text { Absortibitatea } \\
& & P: & \text { Pultsuko potentzia } \\
& & \text { non } & \text { Spot-aren azalera } \\
n: & & \text { Pultsu zenbakia } \\
f=0 & t \in[d t+(n-1) \cdot T, n \cdot T] & d t: & \text { Pultsuaren iraupena } \\
& & T: \text { Pultsuen periodoa }
\end{array}
$$

Bero-iturria kalkulatu ahal izateko laserraren spotak piezaren gainazalean islatzen duen azalera jakin behar da. Azaleraren kalkuluan ezin da laserraren spotaren erradioa erabili zuzenean, izan ere, izpiaren dibergentziaangelua eta materiala erauztean aldatzen den foku-distantzia kontuan izan behar dira. Horrela, testurizatuko den gainazaleko izpiaren azalera azpiko adierazpenaren bitartez kalkulatzen da.

$$
\begin{aligned}
& R: \quad \text { Spot-aren erradioa } \\
& A=\pi \cdot(R+D f \cdot \tan (\gamma))^{2} \quad \text { non } \quad D f: \text { Foku-distantzia } \\
& \gamma \text { : Dibergentzia angelua }
\end{aligned}
$$


Eremu termikoaren kalkulua egin ahal izateko hasierako baldintzak eta ingurune-baldintzak zehaztu behar dira. Baldintza hauek saiakuntza esperimentalak egitean daudenak dira, horregatik hasierako baldintza moduan pieza osoa $25^{\circ} \mathrm{C}$-tan ezartzen da. Hala ere, pultsu bakoitzaren ostean hasierako baldintza hau eguneratzen da hozketa-prozesuaren ostean lortzen diren tenperaturen interpolazioaren bitartez. Ingurune-baldintzei dagokienez, pieza makinan kokatzen den moduak, hau da, euskarriarekin kontaktuan dagoen azalerak, eta laser-izpiak ezartzen dituzte. Horrela, piezaren azpiko aurpegia $25^{\circ} \mathrm{C}$-tan ezartzen da. Laser-izpiaren ingurune-baldintza bero-iturria da, prozesuan zehar dagokion ibilbidean tenperatura igoera bat eragingo du eta. Ingurune-baldintzak laburbiltzen dituen eskema 4. irudian erakusten da. Aipagarria da, alboetako aurpegiei ez zaiela ingurune-baldintzarik ezartzen. Izan ere, laser-testurizazio prozesua hain da bizkorra, non konbekzio- eta erradiazio-galerak mespretxagarriak dira.

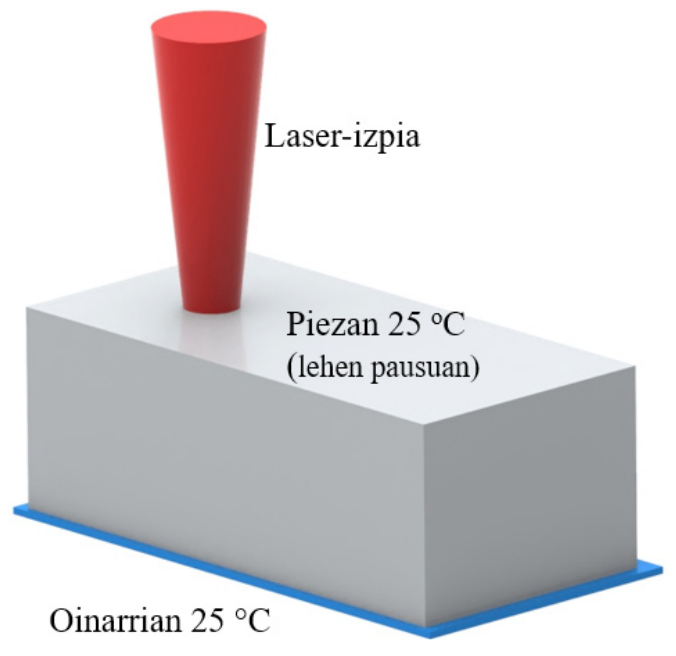

4. irudia. Ingurune-baldintzen eskema grafikoa.

Eremu termikoaren ebazpena egin ostean, tenperatura-aldaketak eragiten duten geometria-aldaketa diferentzia finituen bidez kalkulatzen da. Horregatik, piezaren sare optimizatuaren (5. irudia), hau da, intereseko guneetan sare finagoa duenaren, gainean eremu termikoak eragindako aldaketak aztertuko dira. Sarea lehen ordenako elementu tetraedrikoz osatzen da, elementu txikienaren tamaina $8 \mu \mathrm{m}$ izanik, eta 1,2ko hazkuntza faktorea finkatu da.

Kraterreko material-erauzketa simulatzerako garaian bi estrategia aplikatu dira: alde batetik, elementu osoak kentzea, eta bestetik, lurrundutako nodoak beherantz desplazatzea. 


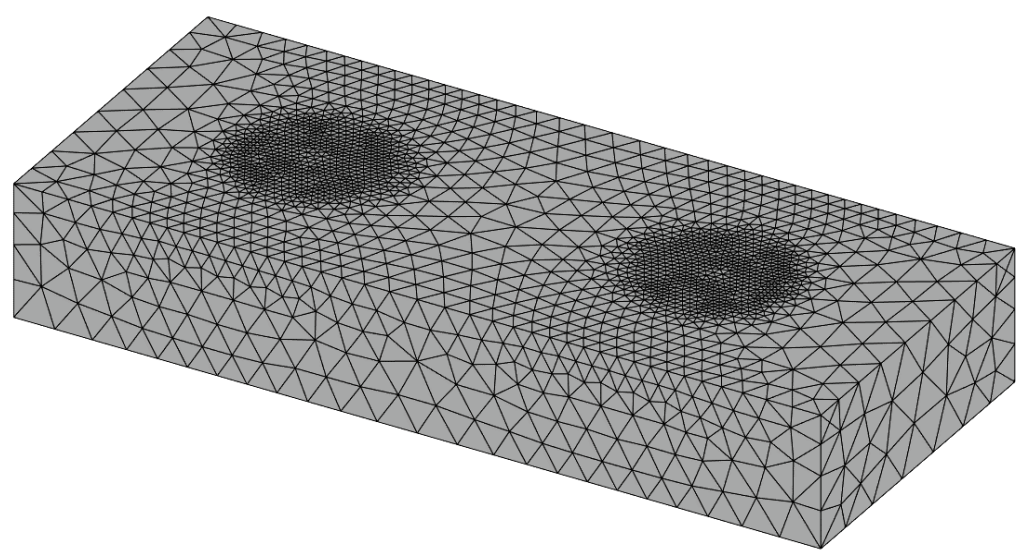

5. irudia. Intereseko guneetan findutako sarea.

\subsection{Lurrundutako elementuak kentzea}

Elementuak kentzeko estrategia honetan elementuen nodoetako tenperaturak aztertzen dira. Horrela, elementu bakoitzaren nodoetako batez besteko tenperaturekin elementuaren tenperatura kalkulatzen da, eta bere balioak materialaren lurruntze-tenperatura gainditzen badu elementu hori ezabatzen da, 6 . irudian ikusi daitekeen moduan.

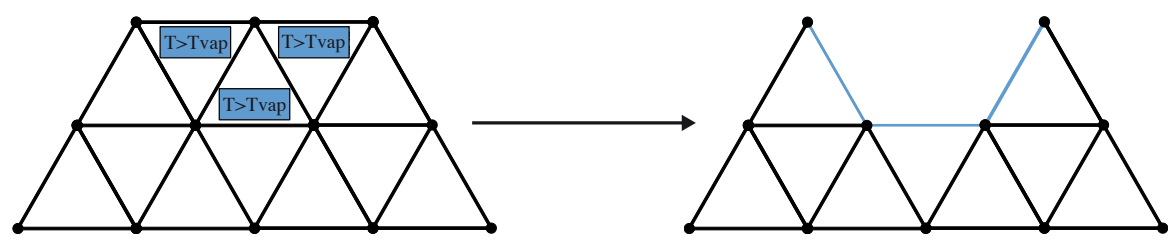

6. irudia. Elementuak lurruntze-tenperatura gailentzean esperotako itxura aldaketa.

Matlab-en exekutatzean lurruntze-tenperaturatik gorako elementuak ezabatu direla ikusten da (7. irudia) eta programaturiko kodearen funtzionamendu egokia bermatzen du. Alabaina, saiakuntza esperimentaletako baldintzak ereduan aplikatzean material-kentze mekanismo hau ez da aktibatzen. Izan ere, elementuak txikiegiak izan beharko lirateke emaitza logiko bat lortzeko, mikrometroa baino txikiagoak, eta horrek ordenagailuaren kostu konputazional handiegia eskatzen du. 
Oihane Murua, Jon Iñaki Arrizubieta, Marta Ostolaza, Aitzol Lamikiz, Eneko Ukar

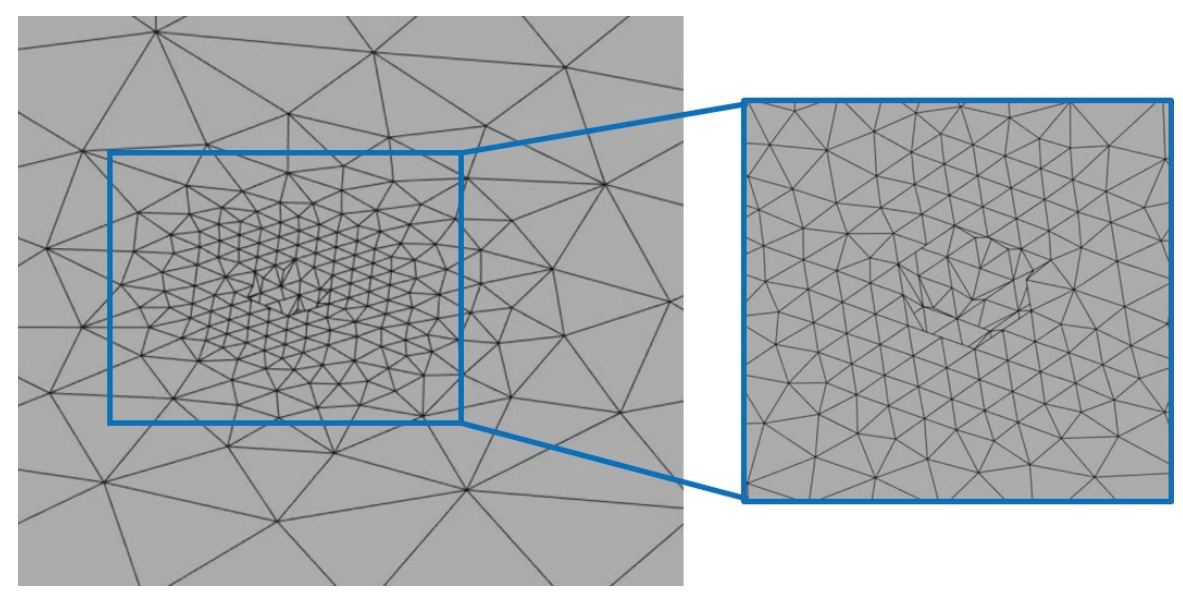

7. irudia. Elementuak kentzean geratzen den geometria.

\subsection{Lurrundutako nodoak desplazatzea}

Materiala kentzeko bigarren estrategia honetan, nodoen tenperaturak lurruntze-tenperaturarekin alderatu eta lurrundutako nodoak beherantz desplazatzen dira. Hau da, laser-izpiak pieza berotzen duen zonako/ eremuko nodoen tenperaturen balioak hartzen dira eta laserraren pultsuak dirauen bitartean, lurruntze tenperatura baino beroago badaude nodoak beherantz desplazatzen dira «dz» distantziako pausoetan (8. irudia). Nodoak paraleloki distantzia txiki bat (dz) mugituz joaten dira eta beren posizio berri bakoitzeko tenperatura lurruntze-tenperaturarekin alderatzen da. Izan ere, nodoa desplazatzen den bakoitzean, bere tenperatura berria interpolazio bidez kalkulatzen da. Nodoak desplazatzen diren distantzia sareko elementu tamainaren eta laserraren bero transferentziaren eraginez esperotako material lurruntzearen arteko konpromisoaren araberakoa da, azken finean elementu zorrotzegiek arazoak dakartzate. Ikerkuntza honetan $0,1 \cdot 10^{-3} \mathrm{~mm}$-koa izan da «dz» aldagaiaren balioa. Desplazamendu-mekanismo hau amaitzeko helduko da puntu bat, non nodoaren tenperatura lurruntzeko beharrezko tenperaturatik behera egongo den eta hor kokatuko da gainazal berria.

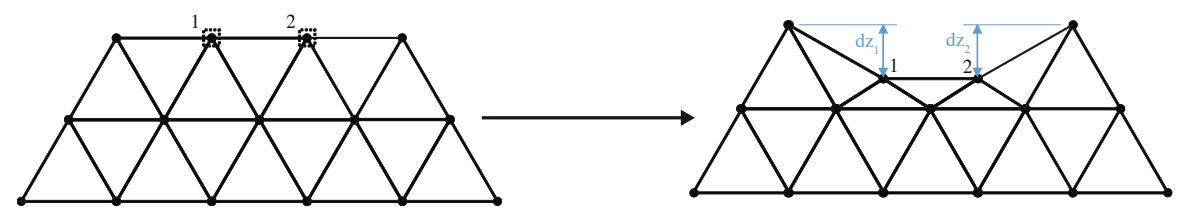

8. irudia. Nodoak lurruntze-tenperatura gailentzean esperotako itxura aldaketa. 
Materiala erauzteko estrategia honen bitartez, elementu osoa kentzean baino geometriaren kontrol zehatzagoa lortzen da.

\section{BALIOZTATZE ESPERIMENTALA}

Laser-testurizazio prozesuaren saiakuntza esperimentalak TruMark Station 5000 makinan egin aurretik Stellite 6ko lagina prestatu behar da. Horretarako, materialaren jatorrizko xaflaren zati bat moztu eta aztergai den probeta sortzen da, jarraian ispilu-akabera lortu arte leuntzeko. Horrela, lortzen den gainazalean mikrometro mailako kraterrak egitean gainazalaren akaberak ez du eraginik izango. 9. irudian honako hauek erakusten dira: (a) saiakuntza esperimentaletako muntaia, eta (b)n aitzinapen-abiadura desberdinetarako lortutako gainazal-testurak. Abiadura desberdinetan saiakuntzak egitearen arrazoia, kraterrak beren arteko distantziaren eragina aztertzea da.

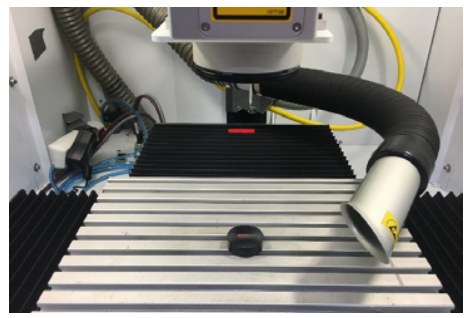

(a)

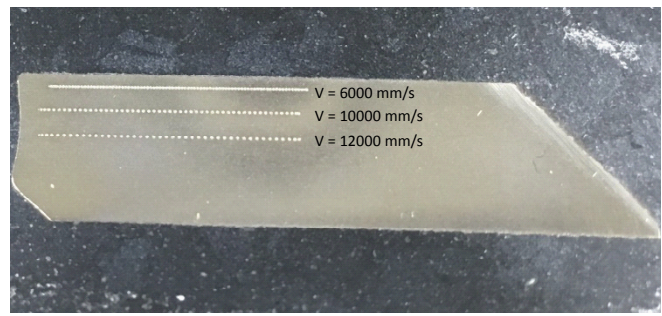

(b)

9. irudia. Balioztatze esperimentala: (a) Laserrak egingo duen egituraketaren aurretiko bista; (b) Laser bidez egindako testura.

Egindako gainazal-egituraketak hobeto aztertzea aldera, mikroskopio konfokal baten bitartez zenbait argazki eta profil atera dira; horien artean 10. irudian erakusten direnak daude. Gainazala leundu ostean kimikoki eraso da Marble erreaktiboarekin, bere gainazalak laser izpiaren absortibitate hobea izateko; horregatik hurrengo irudian Stellite 6aren mikroegitura ikusten da kraterren inguruan.
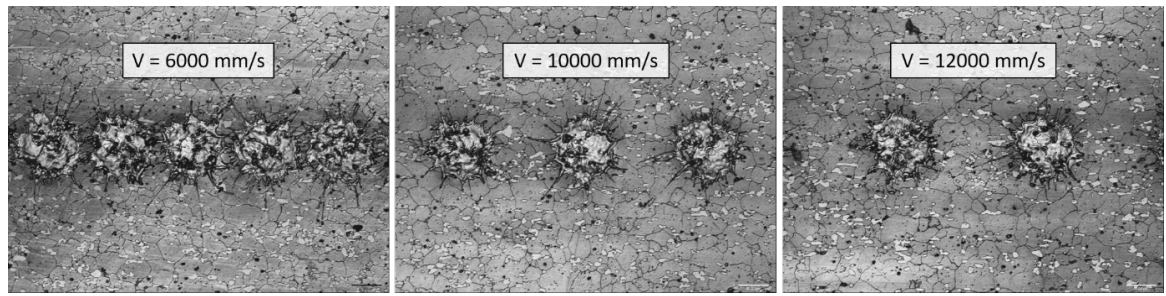

10. irudia. Mikroskopio bidez lortutako kraterren itxura. 
Oihane Murua, Jon Iñaki Arrizubieta, Marta Ostolaza, Aitzol Lamikiz, Eneko Ukar

\section{EMAITZEN EZTABAIDA}

Atal honetan Matlab-eko kodean lortutako emaitzen eta saiakuntza esperimentaletan lortutakoen arteko bateragarritasuna aztertu eta emaitzen inguruko eztabaida zabalduko da. Eredua simulatzean lortutako kraterretako bat 11. irudian erakusten da, berdez dagoen gainazalak beherantz dagoen gunea nabarmentzen duelarik.

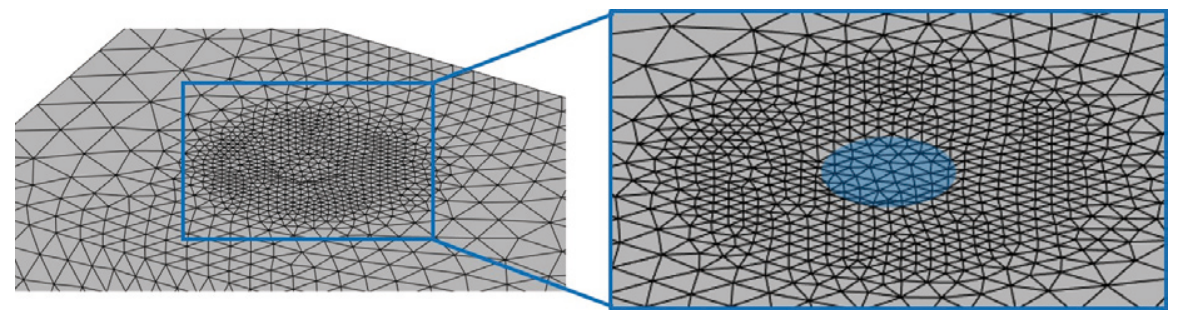

11. irudia. Simulatutako kraterra.

Simulatutako eta saiakuntza esperimental bidez lortutako emaitzak konparatze aldera, hiru puntu aztertu dira. Hasteko, testurizazio-ereduak urtutako materiala kontuan hartzen ez duenez, sinplifikazio honen eragina zenbatetsi behar da. Baita ere, laserraren noranzkoak sortutako kraterren geometrian eragiten duen desbiderapena aztertu da. Eta, azkenik, testurizazio-abiadurak egindako kraterren itxuran eraginik duen ikertu da.

\subsection{Urtutako materialaren adhesioa kraterraren ertzetan}

Kraterren ertzetako urtutako materialaren azterketa krater indibidualen $\mathrm{X}$ eta $\mathrm{Y}$ ardatzetako profilei erreparatuz egiten da, luzetarako eta zeharkako profilak, hurrenez hurren. Testurizazio bidez sortutako kraterraren adibidea 12. irudian ikusi daiteke.

Profilak kontuan izanda, desberdintasun handiena ereduak simulatzen ez duen material itsatsiaren gunean ikusten da. Hala ere, desberdintasun geometrikoak aurkitu arren, eredua gune hori non kokatzen den zehazteko gai da. Gainontzean, ereduaren emaitzak eta esperimentalak oso gertu daude. 


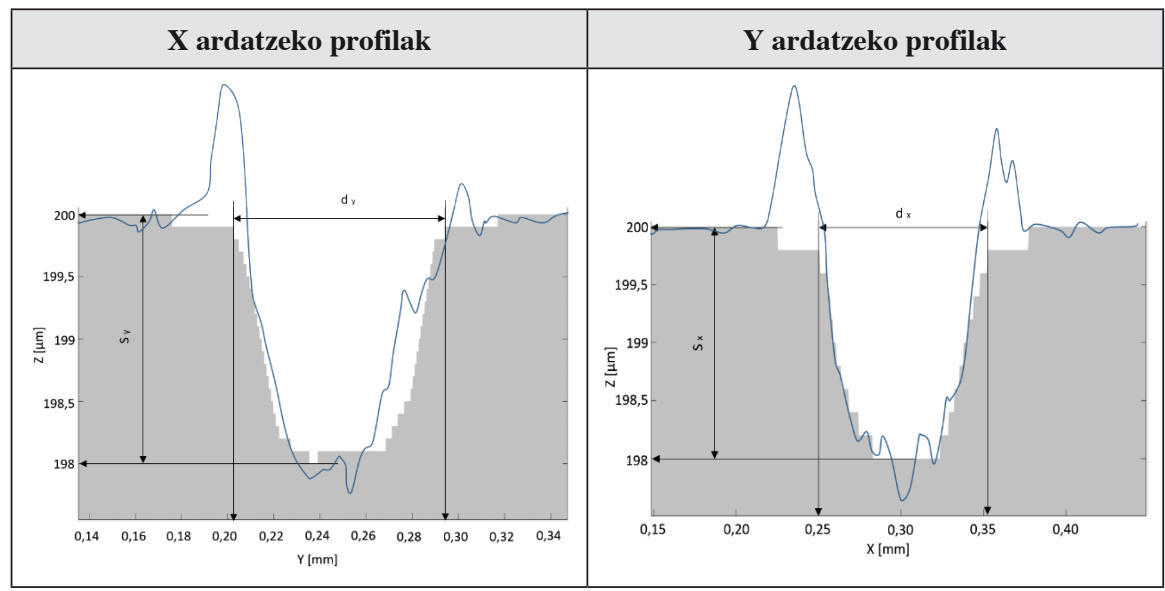

12. irudia. Saiakuntza esperimentaletan eskuratutako (lerro urdina) eta simulazioetako profilen alderaketa (grisez adierazita).

\subsection{Norabidetasunaren eragina}

Laserraren ibilbideak kraterren sorreran izan dezakeen eragina norabidetasunaren bitartez aztertzen da. Horretarako, X eta Y norabideetako profiletan diametroa eta sakonera neurtzen dira. Egindako neurketa hauen batez besteko balioak 3. taulan biltzen dira: alde batetik, ereduaren emaitzak, eta bestetik, saiakuntzetatik lortutakoak.

3. taula. Saiakuntza esperimentalen eta ereduko simulazioen neurriak.

\begin{tabular}{lcc}
\hline & $\begin{array}{c}\text { Ereduaren emaitzen } \\
\text { batez bestekoa }\end{array}$ & $\begin{array}{c}\text { Emaitza esperimentalen } \\
\text { batez bestekoa }\end{array}$ \\
\hline Diametroa X $(\mu \mathrm{m})$ & 100,00 & 96,71 \\
Diametroa Y $(\mu \mathrm{m})$ & 94,00 & 89,02 \\
X Ebaketako Sakonera $(\mu \mathrm{m})$ & 2,00 & 2,47 \\
Y Ebaketako Sakonera $(\mu \mathrm{m})$ & 1,80 & 2,57 \\
\hline
\end{tabular}

Neurketen emaitzen errorea onargarritzat hartzen da: kraterren diametroan $5 \mu \mathrm{m}$-tako eta sakoneran $0,5 \mu \mathrm{m}$-tako erroreak lortu dira, batez beste. Laserrak saiakuntza esperimentaletan eragiten duen norabidetasun efektua, hau da, $\mathrm{X}$ ardatzean mugitzen denez noranzko horretako diametroaren balioa zertxobait handiagoa egitea, ereduaren ematzetan ere gertatzen da. Hala ere, norabidegarritasun-efektu hau oso txikia da eta aztertutako laserizpiaren aitzinapen-abiadura tarterako $(6.000-12.000 \mathrm{~mm} / \mathrm{s})$ lorturiko kraterrak zirkulartzat har daitezke. 
Oihane Murua, Jon Iñaki Arrizubieta, Marta Ostolaza, Aitzol Lamikiz, Eneko Ukar

\subsection{Prozesuko abiaduraren garrantzia}

Eredua abiadura desberdinetan simulatu ondoren, $6.000-12.000 \mathrm{~mm} / \mathrm{s}$, ikusten da lortzen diren kraterren profilak saiakuntza esperimentaletan lortutako emaitzetatik hurbil daudela. Gainera, 10. irudian erakusten den bezala, egiaztatu da abiadura desberdinak erabiltzearen eragina nulua dela, elkarren jarraiko kraterretan ez delako aldamenekoen ondoriozko desitxuraketarik gertatzen. Horretaz gain, abiadura desberdinetan lortutako simulazioen emaitzak saiakuntza esperimentaletan eskuratutakoekin bat datozela egiaztatzen da. Horretarako, 13. irudian abiadura azkarrenean lortzen diren emaitzak erakusten dira, bertan begi-bistaz baieztatu baitaiteke beren arteko desberdintasuna arbuiagarria dela.

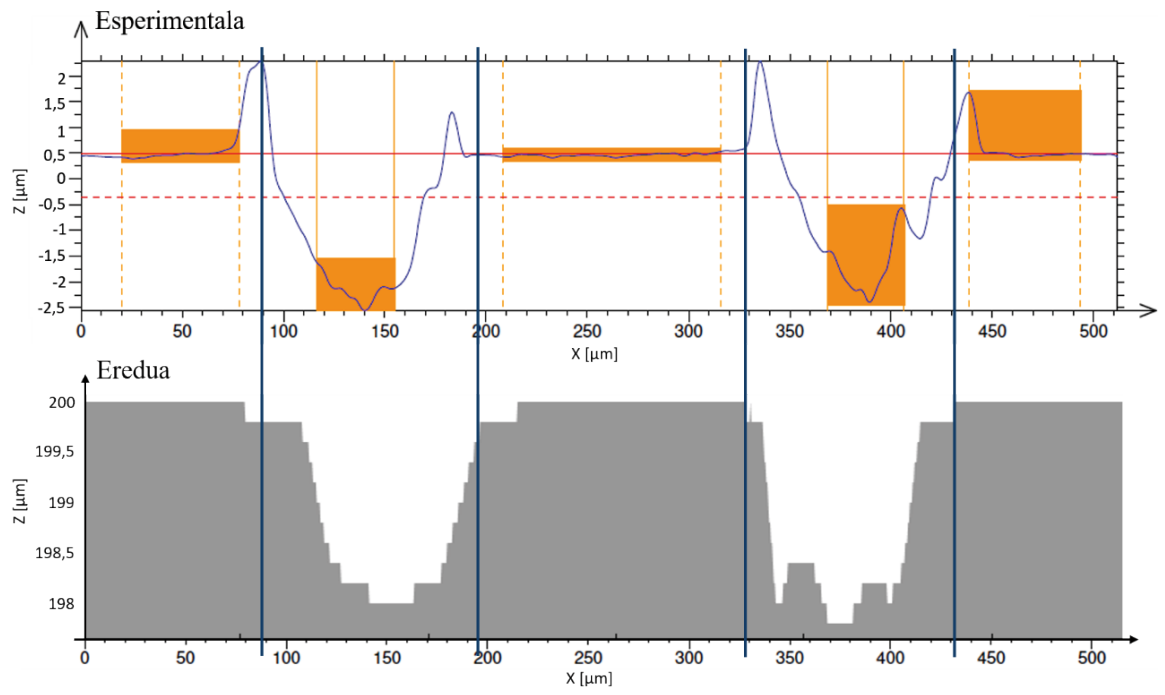

13. irudia. Ereduaren $X$ ardatzeko ebaketa saiakuntza esperimentalen profilarekin batera $(\mathrm{V}=12.000 \mathrm{~mm} / \mathrm{s})$.

Gaineko irudiari begiratuz, ikus daiteke ordenatuetako balioak bat ez datozela. Baina, honen arrazoia da, saiakuntza esperimentaletan profilaren neurriak mikroskopio konfokalak eskaneatzen duenaren araberakoa dela, eta Matlab-en berriz, piezako interes gunearen ebaketa egiten dela. Azken finean, erakutsitako kraterren neurriak balio bera erakusten dutela. Bestalde, saiakuntza esperimentaletako profiletan horiz markatutako guneak mikroskopio konfokalak sakonerak neurtzeko erabiltzen dituen guneak dira. Honelako prozesuetan, sakoneraren balio bakarra lortzea ezinezkoa da, geometriaren gorabeherengatik. Neurketa hauek gune bakoitzeko balioen batezbestekoarekin kalkulatzen ditu. 
Laburbilduz, ereduarekin eta saiakuntzekin lortutako emaitzen arteko errorea onargarria kontsideratuz, garatutako eredua balizkotzat jo da eta bere egiaztapena bukatutzat eman da.

\section{ONDORIOAK}

Proiektu honetan garatutako laser-testurizazio ereduaren bitartez, simulazioak duen garrantzizko eginkizuna gertutik ezagutu da. Prozesu honetan zehar ondorioztatutako zenbait ideiatatik hona hemen garrantzitsuenak:

- Eredua Matlab-en simulatu eta esperimentalki balioztatu ostean lortutako errorea, mikrometro mailakoa, onargarria da.

- Matlab-en PDE moduluaren bitartez eremu termikoaren bero-transferentzia kalkuluak automatikoki egiten direla ikusi da, problema termikoen ebazpenerako erreminta egokia izanez.

- Elementu-tamainaren eta ereduaren erantzute-gaitasunaren arteko konpromiso batera iritsi behar izan da, mikrometro mailako kraterrak testurizatzen direlako. Izan ere, Matlab-eko kodeak behar duen exijentzia konputazionala ordenagailu arrunt batek eskaintzen duena baino handiagoa da.

- Laser-testurizazio prozesuaren izaerak eragiten dituen bat-bateko tenperatura-aldaketen ondorioz, ereduaren egonkortasuna bermatzea konplexua da. Izan ere, alde batetik, prozesu azkar batek dakartzan zailtasunak, eta, bestetik, tenperatura-aldaketa handiak batzen dira.

\section{ESKER ONAK}

Ikerlan hau Eusko Jaurlaritzaren Elkartek 2021 programaren barneko BISUM proiektuaren barnean gauzatu da. Era berean, eskerrak eman nahi zaizkio Espainiako Ekonomia, Industria eta Lehiakortasun Ministerioari, PID2019-109220RB-I00 erreferentzia duen ALASURF proiektuaren finantzaketagatik.

\section{BIBLIOGRAFIA}

[1] Faculty Of Mechanical Engineering. Mechanical Engineering TechnionIsrael Institute of Technology. https://meeng.technion.ac.il/ helbidetik eskuratua, eguneratzen-data 2020.

[2] Etsion, I. 2010. «3. Laser surface texturing and applications». G. K. Nikas en, Recent Developments in Wear Prevention, Friction and Lubrication. 137-157. 
[3] Kumar, V., Verma, R., Kango, S. eta Sharma, V. 2021. «Recent progresses and applications in laser-based surface texturing systems». Materials Today Communications. 26. 2352-4928.

[4] Liu, H., Chen, Y., Wang, X., Meng, X., Fu, Y. eta Cai, L. 2008. «Numerical Simulation of Laser Surface Micro-Texturing». Materials Science Forum. 575-578. 678-683.

[5] Xian, J., Wang, X., Fu, X., Zhang, Z., LiU, L. eta Kang, M. 2018. «A Simple Model to Predict Machined Depth and Surface Profile for Picosecond Laser Surface Texturing». MDPI.

[6] Chevallier, E., Bruyère, V., See, T. eta Namy, P. 2018. «Laser texturing modelling using COMSOL Multiphysics». Excerpt from the Proceedings of the 2018 COMSOL Conference in Lausanne.

[7] Chevallier, E., Bruyère, V., Bernard, G. eta Namy, P. 2020. «Femto-second laser texturing prediction using COMSOL Multiphysics».

[8] Ya, W., PATHIRAJ, B. eta LiU, S. 2016. «2D modelling of clad geometry and resulting thermal cycles duringlaser cladding». Journal of Materials Processing Technology. 230. 217-232. 